Originally published in 2009 in Phenomenology and the Cognitive Sciences, 8, pp. 505-526.

Please refer to original if quoting

\title{
Emotion and ethics: an inter-(en)active approach
}

\author{
Giovanna Colombetti \\ Department of Sociology \& Philosophy \\ University of Exeter \\ $\&$ \\ Steve Torrance \\ Department of Informatics \\ University of Sussex
}

\begin{abstract}
In this paper we start exploring the affective and ethical dimension of what De Jaegher and Di Paolo (2007) have called 'participatory sense-making'. In the first part, we distinguish various ways in which we are, and feel, affectively inter-connected in interpersonal encounters. In the second part, we discuss the ethical character of this affective interconnectedness, as well as the implications that taking an 'inter-(en)active approach' has for ethical theory itself.
\end{abstract}

Keywords: Participatory sense-making - Enaction - Emotion - Empathy - Ethics 


\title{
Emotion and ethics: an inter-(en)active approach
}

\author{
Giovanna Colombetti \& Steve Torrance
}

The most important part of the environment is my fellow-man. (James, 1884, p. 195)

\section{Introduction}

Interpersonal encounters come in a variety of affective tonalities. It is striking how difficult it is to keep an even-minded attitude upon first meeting someone; the other's presence (his or her shape, facial and vocal expressions, body language) irresistibly generates an experience in us, which can be more or less subtly felt, and of course very different in each case (we may be wary, curious, at ease, intimidated, attracted, uncomfortable, etc.). In subsequent encounters, the other's specific mode of being present never ceases to affect us.

This experience, we believe, is part and parcel of what Hanne de Jaegher and Ezequiel Di Paolo (2007) have called participatory sense-making - the sense-making proper to interpersonal interactions that emerges in virtue of the 'coupling' of two or more autonomous systems. More specifically, we believe that this experience reveals the emotional as well as the ethical character of participatory sense-making. For our contribution to this special 'interactive' issue we have thus decided to start exploring these two dimensions in some detail. We think that shifting our attention from the individual to the encounter (as recommended by De Jaegher and Di Paolo) has implications for the enquiry into both emotion and ethical theory. In what follows we will then discuss some of these implications for our respective research areas, as well as how our considerations can be related to one another.

The first part of this paper will focus, in particular, on the affective character of 'feeling connected'. De Jaegher and Di Paolo (p. 490) mention in passing that "interactions often have an affective dimension in the sense that we can feel varying degrees of connectedness with the other". We will elaborate on this claim to characterize these degrees of feeling in more detail; in which sense, and to what extent, are degrees of connectedness 
felt? And, when they are, in which sense are they feelings of connectedness (i.e. how is the other person felt in the encounter)?

The second part of our contribution will focus on the ethical overtones of the intersubjective encounter, and more generally on the connection between emotion and ethics. We will point out for example that the specific way in which an interaction unfolds (the extent to which an encounter is, as we like to put it, inter-enacted) carries with it specific ethical colourings, which are an important focus for normative ethical assessment. These ethical colourings are linked with the affective nature of the encounter, and the pervasively affective character of intersubjectivity is one of the things that helps to make clear how our encounter with the other is a thoroughly ethical enterprise.

Overall, the aim of this contribution is to bring into relief aspects of participatory sense-making that have been, so far, relatively under-examined within the 'enactivist' tradition (Varela, Thompson, and Rosch 1991; Thompson 2007) to which De Jaegher and Di Paolo's work belongs. Whereas we shall take the latter as our source of inspiration and starting point, we will also sometimes indicate ways in which we think it needs to be enriched in order to make room for the varieties of the affective and ethical phenomena we are interested in.

\section{PART I: The affective nature of participatory sense-making}

What is meant by 'sense-making' in the enactive approach? The term appears in later discussions of the theory of autopoiesis (Weber and Varela 2002), and has recently been refined and clarified (Di Paolo 2005; Thompson 2007; Thompson and Stapleton 2009). Briefly, in the enactive approach living systems are characterized as 'making sense' of their world in virtue of their autonomous and adaptive nature. On this view, a living system is by definition concerned with its own continuation, able to discern gradations of value, and motivated to achieve its ideal conditions of viability. A living system thus enacts a perspective or point of view, from which the world is never neutral, but rather always meaningful (and the specific meanings thus enacted depend on the mode of organization and degree of complexity of the organism).

Importantly, from this standpoint making sense of the world is a whole-organism affair; it is the whole organism that makes sense of its environment in virtue of its autonomous structure, rather than a specific mechanism supposedly implementing a cognitive-evaluative psychological capacity (such as the nervous system, or a subsystem 
thereof). This view implies that all living organisms realize some form of sense-making. In addition, sense-making thus conceived comprises cognition as much as emotion (Colombetti, forthcoming). Emotion plays a central role in self-regulation and adaptivity (Damasio 1999, 2003; Panksepp 1998), ${ }^{1}$ and the enactive approach treats cognition and emotion not as separate systems, but as deeply integrated biological, psychological and phenomenological levels (Colombetti 2007, forthcoming; Colombetti and Thompson 2008). As De Jaegher and Di Paolo (2007, p. 488) also remark, "sense-making is a[n] ... affect-laden process grounded in biological organization ... Hence it does not promote a fissure between affect and cognition".

Recent developments of the notion of sense-making include De Jaegher and Di Paolo's (2007) discussion of what they call participatory sense-making. The latter emerges in the concrete encounter of two or more coupled autonomous systems; crucially, the process of participatory sense-making has its own autonomous dynamics (or interaction-autonomy, as we call it below) that conditions, enables and constrains the autonomy of individual agents. De Jaegher and Di Paolo illustrate and discuss this phenomenon drawing on a variety of studies in various disciplines; within the enactive approach, related ideas can be found in Evan Thompson's $(2001,2007)$ analysis of intersubjectivity and empathy (discussed below). Although not explicitly phrased in terms of 'participatory sense-making', Thompson's work is relevant in that it distinguishes various ways in which we experience, understand and imply each other as embodied and enactive systems.

In this first part of our contribution we are particularly interested in exploring the way in which, specifically, affectivity plays itself out in participatory sense-making. De Jaegher and Di Paolo (p. 490) mention in passing that "interactions often have an affective dimension in the sense that we can feel varying degrees of connectedness with the other". Yet if sense-making, as just mentioned, is inherently affective already at the level of the individual organism, then participatory sense-making is not just 'often' but rather always affect-laden; autonomous organisms bring to their encounter their own forms of cognitive as

\footnotetext{
${ }^{1}$ For Damasio emotion is an organismic process of self-regulation aimed at maintaining homeostasis; emotion thus conceived also provides action-guiding values, drives and preferences. Panksepp sees emotion as a collection of meaning-generating and adaptive mechanisms underpinned by specific neural and endocrine processes; emotion allows the organism to adapt to life-challenging circumstances, is constitutive of action and organizes diverse behaviours, and modulates the activity of perceptual systems.
} 
well as affective understanding, and as a consequence affectivity is perturbed and transformed as the encounter unfolds, and as it generates its own meaning.

In what follows, we shall thus pay special attention to the place of affectivity in participatory sense-making, and to the nature of 'feeling connected' in concrete, face-to-face encounters. How can we better characterize the feelings of "various degrees of connectedness" hinted to by De Jaegher and Di Paolo? In which sense and to what extent are degrees of connectedness 'felt' and, when they are, in which sense are they feelings of connectedness (i.e. how is the other person felt in the interaction)? As we will see, some enactivist theorists have already drawn useful distinctions between various modes of intersubjectivity and empathy, and we shall use some of this work as a starting point for our own. Our specific aim will be to bring into relief the emotional dimension of these various modes of inter-enaction, and to begin discussing in some detail how this dimension affects, and is affected by, interpersonal encounters. ${ }^{2}$

\section{Sensing-in}

Thompson's $(2001,2007)$ work on intersubjectivity is particularly useful here. By drawing on a variety of phenomenological and empirical studies, he distinguishes different levels of empathy or ways in which we 'grasp' the other in face-to-face encounters. His distinctions can be used to analyse how affectivity enters intersubjectivity, and vice-versa, thus helping us provide an account of what it is like to 'feel connected' in participatory sense-making.

2 One may wonder why we want to embark in this enterprise, given that social and developmental psychologists are already studying emotion in intersubjectivity. This is true, of course, and their work is very important for the development of the enactive approach itself (as the forthcoming discussion will show). Yet, first, the enactive approach is a broad theoretico-philosophical framework (see Thompson 2007) which is not reducible to hypotheses in social or developmental psychology, and which rather guides work in various disciplines (psychology, neuroscience, robotics, etc.) and helps make sense of their empirical findings. Second, the enactive approach has said little so far on the topic of emotion; the work on empathy and intersubjectivity that we mention below has not looked at emotion in much detail (if at all), and our aim in this paper is to expand and enrich existing accounts by showing how they can be used to analyze the conceptual relationship between affectivity and intersubjectivity. 
One empathic process he discusses is what Edith Stein (1964) calls 'sensual empathy' or 'sensing-in', in which we directly perceive the existence of the other as a bodily subject of experience, rather than as an object. Sensual empathy is passive and involuntary. As Stein remarks, a hand does not appear to us as resting on the table in the same way as the book next to it does; we directly and involuntarily perceive the hand (and not the book) as a locus of awareness with its own field of sensation, including the possibility for it to be affected in specific ways (see Thompson 2001, p. 17). Sensing-in thus represents an immediate feeling of being-connected, which seems to us to be best characterized as tacit or pre-reflectivenamely as an experience that is normally (in everyday encounters) not thematic and reflected upon, but that nevertheless characterizes our awareness of the other as such.

At this level of connectedness, we can think of an intersubjective encounter as one in which an autonomous organism makes sense of the other as another autonomous organism with its own point of view and possibilities for sense-making. This mode of connectedness strikes us as clearly affect-laden in at least two ways: first, each subject senses-in the other as a locus of sentience and sense-making, including affective experiences and possibilities for further feelings; second, this process is itself an act of sense-making which comes with its own affective colouring. ${ }^{3}$

Here we take sensing-in to be a fundamental pre-reflective affective experience involved in all forms of participatory sense-making. Once this basic level of feeling connected has been identified, we think it is important to distinguish further between: (i) degrees of connectedness in which affective resonances (attunement, coordination, etc.) with the other prevail; (ii) emotion experiences in which the other's alterity comes into relief; and (iii) emotion experiences that involve some form of imaginary transposition. These cases correspond broadly to three other levels of empathy identified by Thompson $(2001,2007)$ namely affective and sensorimotor coupling (the most basic level of connectedness between lived bodies), imaginary transposition into the other's place, and understanding of the other

\footnotetext{
${ }^{3}$ A terminological clarification may be useful here. We use the terms 'feelings', 'affect', 'affective experience' and 'emotion experience' as synonyms, to refer to the phenomenological-experiential aspect of emotion. When we use the term 'emotion' we refer to a broader phenomenon that encompasses emotion experience, as well as subpersonal neural and bodily events, and/or expression and behaviour (our terminology is thus similar to the one proposed by Damasio 2003).
} 
as an alter for whom I am an other. ${ }^{4}$ We think that distinguishing these levels is important for a complete inter-enactive account of 'feeling connected'. Participatory sense-making as discussed by De Jaegher and Di Paolo pertains mainly to the first of these levels, as it emphasizes motor coordination and attunement. Yet the variety of our affective experiences reveals modes of connectedness that, we believe, go beyond feelings of attunement. Acknowledging this variety does not imply, of course, that coordination and attunement are not as entrenched in face-to-face encounters as De Jaegher and Di Paolo emphasize. What we want to call attention to here, however, is that human 'feelings of connectedness' involve a complex interplay of various levels of empathy or other-grasping. This complex interplay comes into relief as soon as one starts reflecting on the nature of affective experience in interpersonal encounters.

\section{Affective resonances}

We shall use the term 'affective resonances' for cases of affective inter-enactivity in which mirroring, mimicking and coordination are relatively smooth and undisturbed, and accompanied by feelings of flow and of being attuned to one another.

In terms of subpersonal mechanisms, there is robust evidence by now showing that concrete encounters are characterized by automatic processes of affective mimicry and neural mirroring. Dimberg et al. (2000), for example, have shown that the non-conscious perception of facial expressions of emotions induce in the perceiver distinct facial reactions that mimic (at least parts of) the expression perceived. ${ }^{5}$ Specifically, they found that non-conscious perception of sad faces increased activation in the corrugator supercilii muscle (considered a feature of facial expressions of 'negative' emotions), whereas non-conscious perception of happy faces increased activation in the zygomatic major muscle (considered a feature of

\footnotetext{
${ }^{4}$ Thompson (2007) also talks of the moral perception of the other as a person; we deal with this level of empathy in the second part of this paper.

${ }^{5}$ One way of inducing non-conscious perception of visual stimuli is with the 'backward masking' technique. Dimberg et al. (2000) flashed pictures of happy, neutral or sad facial expressions for 30 milliseconds, followed by a picture of a neutral expression (flashed for 5 seconds). The technique is called 'backward masking' because only the second stimulus lasts long enough to be consciously perceived, and its perception is thus said to 'mask' the perception of the previous stimulus.
} 
facial expressions of 'positive' emotions). There is also evidence that the perception of another's expression of disgust activates the same neural areas involved in one's own expression and feeling of disgust - that is, the perception and the production of the expression of disgust share the same neural mechanisms (i.e. the anterior insula, see Wicker et al. 2003). Likewise for the perception and production of pain expressions, both of which have been found to activate the cingulate cortex (Hutchinson et al. 1999). (For earlier evidence of related phenomena see Hatfield, Cacioppo, and Rapson 1994).

Now, we do not know how these automatic mechanisms of reciprocal attunement relate to feelings of connectedness; furthermore, whether they play any role in understanding others is highly debated. From our perspective, it is natural to interpret the spontaneous mirroring of the other's behaviour, expression and neural activation as subpersonal substrates for sensing-in, which allow and facilitate further modes of inter-enaction. One such further mode would be what Daniel Stern (1985/2003) has called affect attunement. Stern uses this term to refer to (what he deems to be) behaviour expressive of a shared affective state. He illustrates affect attunement with various examples; here is the first one, in his own words:

A nine-month-old girl becomes very excited about a toy and reaches for it. As she grabs it, she lets out an exuberant 'aaaah!' and looks at her mother. Her mother looks back, scrunches up her shoulders, and performs a terrific shimmy with her upper body, like a go-go dancer. The shimmy lasts only about as long as her daughter's 'aaaah!' but is equally excited, joyful, and intense. (Stern 1985/2003, p. 140)

The mother in this example is not mirroring or matching the child's behaviour; rather, she is reproducing cross-modally some of its dynamic features. According to Stern, the mother's response is an attunement to the child's affective state, which allows her to participate in the child's experience. Leaving aside Stern's (explicit) assumption that affective states are 'internal' feelings 'behind' 'external' behaviour (a Cartesian assumption we do not endorse), we can see these phenomena of affect attunement as manifestations of the participants' willingness to maintain an explicit feeling of connectedness and to keep the encounter going. The mother in the above example senses-in the child and his or her affective state, and lets herself share it by reproducing, cross-modally, some of the dynamic features of the child's behaviour (typically intensity, timing, and shape). The affective resonance thus achieved reinforces the feeling of connectedness between the participants. 
Automatic subpersonal mechanisms for mimicking and mirroring can thus be seen as enabling an initial coupling and coordination of self and other, ${ }^{6}$ which, once reinforced and established, can be enriched via the introduction of variations and gradual differentiation, moving on towards more complicated dialogical forms of interaction. Stern (1985/2003) notes that affect attunement as a modality of mother-infant interaction appears when the infant is about nine months old; it is at this stage that the mother begins to complicate her responses to the infant, by adding variations (including cross-modal ones) to her previous, more imitation-like behaviour. As Stern puts it (op. cit., p. 143), "affect matching with its probable basis in 'motor mimicry' [...] cannot alone explain affect attunement, although it may well provide one of the underlying mechanisms on which that phenomenon is founded".

It is important to note that from evidence of increasing complexity and variations in mother-infant interactions, it does not follow that affective mimicry and mirroring are somehow 'transcended' and disappear in adulthood. As Shaun Gallagher suggests, what Colwyn Trevarthen (1979) originally called 'primary intersubjectivity' (i.e. a set of embodied and affective skills involved in non-conceptual and pragmatic understanding of others) is not just developmentally primary, but "remains primary in all face-to-face intersubjective experiences, and it subtends the occasional and secondary intersubjective practices of explaining or predicting what other people believe, desire or intend in the practice of their own minds" (Gallagher 2001, p. 91). The studies of affective intersubjectivity mentioned above (and many others) certainly support this claim. Not only is there much evidence of affect attunement in parent-infant interactions; adult interactions also involve a great deal of automatic affective and bodily mirroring-as well as, as we all know, shared emotion experiences which are very much 'felt'.

It does not follow either that 'imitation-like behaviour' is less active and/or engaged than Stern's affect attunement and more complex interactional dynamics. Feelings of

\footnotetext{
${ }^{6}$ Cf. Thompson (2001, p. 17): "empathy is [...] the experience of another as an embodied subject of experience like oneself. This sort of empathy occurs through an immediate 'pairing' or 'coupling' of the bodies of self and other in action. We find here a clear connection between phenomenology and recent cognitive neuroscience, in particular to the mirror neuron findings. [...] the mirror neuron findings indicate some of the biological depth of empathy at the level of the passive association of the living bodies of self and other in embodied action".
} 
connectedness are present from birth, in all participants. We know that newborns respond with distress to other infants' vocalizations of distress (and not to their own; see Dondi et al. 1999). As Vasu Reddy (2008, esp. chapter 5) argues, we have good reasons to think that very young children do not just 'passively' imitate or mirror the adult's expressions; they engage emotionally from birth, with evidence of initiating communication and turn-taking already at 2 months, and are clearly responsive to the caregiver's engagement and emotional state (as shown for example by Ed Tronick's 'still face' experiments mentioned by De Jaegher and Di Paolo 2007).

\section{Alterity}

Our discussion so far has been very much in line with De Jaegher and Di Paolo's (2007), as well as with Thompson's (2007, pp. 393-5) analysis of the affective and sensorimotor coupling in empathy; phenomena of affective resonance certainly occupy a central place in interpersonal encounters throughout the lifespan. Yet we also think it is important not to overlook the alterity of the other and the implications this condition has for inter-enaction and affectivity. As Zahavi (2001, p. 165) reminds us, "the confrontation with radical otherness is a crucial and non-negligible aspect of what intersubjectivity is all about"; and as Thompson (2007, p. 393) discusses, empathy involves the "understanding of you as an other to me, and of me as an other to you". De Jaegher \& Di Paolo (2007) also acknowledge this point towards the end of their paper (cf. pp. 503-4), when they note that whereas sometimes interactions with others are smooth and effortless, other times the other's alterity comes to the fore and we experience her or him as relatively more "opaque" (on p. 504 they nicely characterize the other as "a protean pattern with knowable and unknowable surfaces and angles of familiarity"). Indeed, we think that focusing on the affective dimension of intersubjectivity reveals the interplay of transparency and opaqueness in other-experiences in all its complexity.

Jean-Paul Sartre (1969) famously emphasized the conflictual nature of our frontal encounters with others (thus criticizing Heidegger's characterization of Dasein as fundamentally Mitsein; see Zahavi 2001). Sartre's well-known argument to illustrate the other's transcendence draws on an emotion experience, the experience of shame: in shame, I experience myself as being observed and evaluated by an other; this experience discloses the other as a radical alter, namely as the one which I am not, and for whom I am an object. 
Sartre's discussion is useful because it reminds us that feelings of connectedness are not always pleasant or conducive to further bonding; indeed, sensing-in the other as another subject can also be accompanied by feelings of antipathy and the impulse to disengage. This is an aspect of participatory sense-making that should not be overlooked. At the same time, however, we do not think that Sartre's account does justice to the complex and multi-layered nature of the experience of shame. In particular, we disagree with his emphasis on the radically transcendent and conflictual nature of the alter that is revealed in shame. After all, shame also involves sensing-in the other not as an object, but as another I with whom we can interact and who is herself a source of feeling. Moreover, during shame we share with the other the evaluative experience of an act as shameful; we are thus deeply affectively connected to the other via this joint appraisal. That shame involves a dimension of affective resonance becomes particularly evident in those interesting cases of 'vicarious embarrassment' (what Spanish speakers call vergüenza ajena; see Iglesias 1996) in which we feel ashamed 'for the other' when we witness the other behaving inappropriately on a social occasion. Although we are evaluating the other from an 'outsider's perspective', so to say, the other is not a mere object for us; indeed, we cannot help sensing-in the other and feeling ashamed ourselves.

The case of shame thus illustrates well the complex interplay of various degrees of connectedness that can be simultaneously experienced in participatory sense-making. But many other feelings involve such an interplay. For instance, we would regard feelings of antipathy as involving a form of 'dissonant connectedness' in which sensing-in and sense of alterity are subtly entwined: it is the other as sensed-in that we resist and want to disengage with. Or consider what can be seen as the other side of shame, i.e. pride. Pride in our own qualities and possessions, as David Hume (1739/2003) already noted, is increased by the other's admiration. Hume explained this phenomenon by appealing to our capacity to sympathize; sympathy makes the other's admiration "intimately present to us" (op.cit., p. 203), which in turn augments our pride. So, as for shame, in pride our experience depends on both grasping the other as an autonomous alter with his point of view, and sharing a common appraisal.

\section{Imaginary transpositions}

We shall now consider the role, in emotion experience, of what Thompson (2007, p. 391) calls 'imaginary transposition'. Thompson uses this term for types of empathy in which "I 
mentally transpose myself to the other's place to comprehend the object of the subject's experience from his or her point of view" (p. 388); this process allows us to take up the other's perspective, including the contents of her or his mental states. ${ }^{7}$ For our purposes, what is interesting is that this further mode of connectedness adds up to the variety of our interenactive feelings. The capacity we have to take up the other's point of view and mental contents, together with the feelings of connectedness given through sensing-in, affect attunement, etc., results in interestingly complex affective experiences.

Consider feelings of envy, for example, in which we feel hostility towards an other whose point of view and contents of experience we are nevertheless taking up, and in whom we are also projecting ourselves. In envy, we sense the other's pleasure in possessing the good we desire, via a phenomenally inextricable mixture of imagining and taking up the other's experience from her point of view, and imagining ourselves in her position (as some have argued, if we just desired the good the other possesses, we would be greedy not envious; see e.g. Ben Ze'ev 1990). Jealousy can also involve a very complex mixture of sensing-in, alterity, and imaginary transposition. In some cases (but the scenarios can vary of course), the jealous lover senses-in the loved one and the rival, with their potentialities for feelings for each other. Such sensed-in feelings are familiar and alien at the same time. The jealous lover knows what it is like to love the loved one, and to be reciprocated by her or him. Yet at the same time the alterity of the loved one and of the rival makes it impossible for the jealous lover fully to experience the nature of their relationship; the jealous lover may then try, more or less consciously and willingly, to fill this gap by engaging in imaginary transposition (which is likely to increase the jealousy). Significantly, jealousy is for some lovers a strong erotic enhancer, and some even find that they can fuel their passion only by getting involved in triangles (Person 1988).

Last but not least, consider the capacity to feel sympathy towards others. In our view, this capacity also depends on some mixture of sensing-in and imaginary transposition; it is because we immediately perceive the other as a locus of feelings, and because we have (at

\footnotetext{
7 This process is sometimes called 'cognitive empathy', but we shall not adopt this terminology here because we think it may lead to overlook the inherently affective nature of intersubjectivity.
} 
least some) insight into the contents of his or her feelings, that we can develop the specific experience of sympathy towards him or her. ${ }^{8}$

We can support this claim by looking at the techniques used by Buddhist practitioners to cultivate sympathy towards others; significantly, these techniques employ some kind of imaginary transposition. As Alan Wallace (2001) explains, in Indo-Tibetan Buddhism there is a matrix of practices known as 'the Four Immeasurables' which are used to cultivate a moral stance towards others; the English terms that indicate the four states one should cultivate and enhance in oneself are 'loving kindness', 'compassion', 'empathetic joy', and 'equanimity'. Of particular interest here is the second state (compassion), and the meditative technique employed to attain it. Compassion, as Wallace defines it, is a yearning that other people be free from attachments and suffering. In order to develop compassion towards all beings, Buddhist practitioners engage in meditative-imaginative processes in which they initially cultivate compassion for those who are wretched and miserable (the 'easiest' case), then they move on to direct this feeling towards themselves, then towards a loved one, then towards a 'neutral' other, and eventually to hostile others. This technique (which is used to facilitate the generation of compassion in concrete encounters) requires taking up the other's perspective and imagining what it feels like to be in the other's situation, and it exploits the affective power generated by the act of imaginary transposition to induce equally powerful feelings towards oneself and others. As Wallace puts it, "in the cultivation of compassion, empathetic sadness or grief acts [...] as fuel for the warmth of compassion" (op. cit., p. 219).

In sum, then, the variety of our feelings reveals a complex interplay of degrees of connectedness - from subpersonal automatic mechanisms of mirroring and mimicking, to sensing-in, affect attunement, sense of alterity and imaginary transpositions. We regard all of these as part and parcel of participatory sense-making; that is to say, as ways in which we make sense of one another as autonomous, enactive organisms. We now want to move on to examine the link between the pervasively affective nature of participatory sense-making, and its ethical dimension. The discussion of compassion seems to be a good place to introduce

\footnotetext{
${ }^{8}$ For the different view that sympathy does not require empathy or other modes of imaginary transposition, see Goldie (2000). Goldie draws several distinctions between ways in which we think about others' emotions, which we do not have room to discuss here. Note however that Goldie's notion of empathy requires, among others, enacting the other as a narrator; this requirement, we agree, is not necessary for sympathy.
} 
this theme; perhaps more than any other experience mentioned so far, compassion reveals the ethical or moral character of participatory sense-making. Yet generally we do not think that there is a well-defined borderline between moral and non-moral emotions; as inherently affective, participatory sense-making also comes with ethical colourings or overtones, which we now want to bring to the fore explicitly, and discuss in relation to existing ethicophilosophical approaches. As we will also suggest, the inter-enactive approach, with its emphasis on interaction rather than on individual agents, can offer an interesting new slant to ethical theory that complements existing accounts.

\section{PART II: Inter-enaction and the ethical}

\section{Emotion in ethics}

It goes without saying that there are deep linkages between ethics and the emotions. So it is valuable to start by briefly reminding ourselves of the role played by emotions in certain historical accounts of ethics. Not so long ago Antonio Damasio (2003) brought the work of Spinoza to the fore, suggesting that the latter's theory of affect has important things to tell contemporary mind scientists. In fact Spinoza's Ethics (1677/1996) posed a radical challenge to conventional thinking about morality, because of his opposition to orthodox theism, and his uncompromising determinism. Spinoza rejects any ethical account that requires an assertion of freedom of the will; in its place he provides an ethics based upon a different kind of freedom, the freedom of self-knowledge. The kind of self-knowledge Spinoza proposes has, at its core, the quest for understanding our emotions, for understanding both how some emotions can enslave us, and how others can increase our autonomy. So the distinctive ethical framework that Spinoza offers (one which is, regrettably, given less exposure than it deserves) carries at its heart a drive to affective self-reflection (Torrance 2005).

Emotions, particularly the distinctive moral emotions, figured prominently in the moral psychology and normative ethics of a number of $18^{\text {th }}$ century theorists, such as Lord Shaftesbury (1737/1977), Francis Hutcheson (1728/2003), David Hume (1739/2003) and Adam Smith (1759/2002). This tradition of thinking about morality revolves around the idea that our ethical judgments are driven by 'moral sentiments' primarily, and by 'reason' secondarily. The debate over the relative place of reason and passion within ethics is one which has dominated ethical theory over much of the time since that period. 
In recent times the dominance of cognitivism within philosophy, psychology and related fields has influenced thinking about ethics, at least within the Anglophone world. During the period of high positivism in the mid- $20^{\text {th }}$-century, ethics was seen as laying firmly outside the domain of the cognitive or the rational. Thus for 'emotivists' such as Ayer (1936) and Stevenson (1944), moral judgment was closely allied with affective expression and response, which had the effect, more or less, of consigning it to an intellectual backland where it did not need to be given serious epistemic consideration. After the demise of emotivism much moral philosophy came, as if to compensate for emotivist non-cognitivism, to stress deliberative and rational aspects of the ethical over the felt or affective aspects (there have been notable exceptions to this trend, including Williams 1972; Nussbaum 2001; Blackburn 1998).

No-one should deny the importance of reason in ethics; nor indeed could there be any adequate account of emotions which did not take account of the ways in which emotions can be subject to various dimensions of rational scrutiny and criticism (e.g. consistency, factual accuracy, appropriateness to object, and so on). Nevertheless much ethical discussion in recent decades has proceeded as if emotion was either absent from moral thinking or was an aberration. This excessively intellectualist attitude has been subjected to much criticism by those arguing for a more fully-rounded view of ethics. For example Bernard Williams observed that strongly-held moral views tend to be expressed in terms such as 'disgusting', 'outrageous', 'admirable', etc. Indeed, as he pointed out, “violent language and obscenities play a larger part in people's remarks in appraisal of human conduct than one would gather from a textbook on moral philosophy" (Williams 1972, p. 219).

On a more evolutionary note, there has also been fruitful work on the many significant features of human ethical experience and activity-and in particular on the affective aspects of human ethical experience-which are to be found in our pre-human forebears (see, for instance, de Waal 2006).

\section{Varela on ethical 'knowhow'}

What about the enactive point of view and ethics? In fact we can see enaction as giving a fresh perspective on the traditional 'reason versus emotion' dialectic in ethics. As pointed out in the previous section, enactivist accounts of sense-making imply that cognition and emotion should not be seen as two strictly divorced kinds of processes. Rather, any episode of cognition will have its affective component (and of course vice-versa). This has important 
implications for the 'reason-emotion' debate in ethics. For if it is true of cognitive rationality in general that it is inevitably intertwined with the affective, then it must also be true of ethical cognition and sense-making. Making sense of the moral domain is to be seen as a cognitive-affective process, not as an enterprise of some more limited ratio-cognitive sort.

Discussions of the ethical have seldom occurred in a very explicit way within the enactive tradition. But, arguably, a deeply ethical inspiration ran through The Embodied Mind (Varela, Thompson, and Rosch 1991). In the Introduction (p. xv) the authors say that the book begins and ends with the conviction that mind science needs to "encompass ... the possibilities for transformation" in lived experience. Ethical transformation was at least part of that package. One important way in which the book unfolds an ethical theme is in its emphasis on Eastern mindfulness traditions (which develop in ways that resonate deeply with the radicalism of Spinoza's ethics). This is found particularly in the discussion of compassion and related topics in later parts of the book.

In his subsequent book Ethical Knowhow (1992/1999), Francisco Varela builds on many insights from the 1991 volume, in a way that directs them particularly to the domain of ethics. Specifically, he extends the critique of narrowly cognitivist and computationalist accounts of the mind found in the 1991 volume, to an account of ethical experience and cognition. Varela specifically criticizes what he sees as a morality of abstract 'prescriptive principles' prevailing in thought on ethics. He takes new developments in situated cognitive science and in neurodynamics (plus, of course, strands in Eastern mindfulness/awareness traditions) to enable a move from a morality dominated by the rightness or wrongness of deliberate, intentional actions, to a more situated, affectively engaged ethics. Spontaneous, immediate actions, and a moral knowhow based on "the hinges of the immediate present" such as a person's unthinkingly rushing to help at the scene of an accident in the street - play a more important role within this discussion than deliberative, principled actions in accordance with maxims. The argument in Ethical Knowhow thus implies an opposition to the idea that 'moral cognition' could be factored neatly into a 'strictly' cognitive and affective component, where the former is seen as the wheat and the latter as the chaff.

\section{Inter-enaction as a new approach to ethics}

For all these reasons and more, it cannot be doubted that emotion plays an intimate and indispensable role in the ethical sphere - not least because, as already stressed, the affective and the cognitive are strongly intertwined. Moreover we claim that it is just as important to 
recount an inter-enactive story for ethics as it was, above, for the emotional sphere. So we will explore some ways in which the study of social interaction, when developed on enactive lines, can illuminate the study of ethics (the reverse also seems true: the study of ethics has a lot to contribute to an enactive account of social interaction-we expand on this below). The relations between the three principal domains of our discussion-emotion, ethics and social interaction - are highly complex and multifaceted, so what we are presenting here must be seen as very much a first outline sketch.

We believe an inter-enactive account, and particularly the key notion of participatory sense-making, can offer an important new approach to ethics, that could, with sufficient development, be seen as taking a place alongside the various primary ethical 'paradigms' that it is common to distinguish within ethical theory-namely, utilitarian (or consequentialist) theories, deontological (or duty-based or 'Kantian') theories, and virtue-based theories. We do not want to say that an inter-enactive account of ethics should be considered as a replacement for all of these 'paradigms'. Indeed to put it that way presupposes that it is useful to see the various paradigms as mutually antagonistic competitors for the 'correct' story about what ethics is or 'ought' to be about. It is true that the staunchest defenders of each of these approaches would see their approach in such a competitive light, but we believe a more reasonable view is to see each approach as offering a distinctive and important contribution to an overall picture. So the ethical account centering on participatory sensemaking and interaction should be seen as supplementing other accounts, as making good some deficiencies and silences in those accounts, rather than as supplanting them.

A principal criticism that we would make of the standard approaches to ethics is that they are each too exclusively individuocentric in nature, too focused on the alone-in-a-crowd single agent (this is true both in virtue of what they say and of what they leave out). Such views take ethics to be centrally about discerning the right way for an individual agent to act (or, in the case of virtue ethics, the right kind of person an individual person should try to be), so that they variously look for the best results for an individual ethical agent to achieve, for the right rules or duties for an individual agent to follow, or for the most appropriate character or dispositions for an individual to seek to cultivate in life. The collective ethical life is thus built out of an aggregation of individual ethical directives, where (hopefully) the whole works in relative harmony. What is omitted in most such accounts is any exploration of the deep ethical ramifications of the participatory, collective dynamics of human interrelations per se, as opposed to the ethical significance of individual actions and their simple aggregations. 
The problem with this is not that these individuocentric perspectives are irrelevant to ethics, but rather that an account of ethics that lays exclusive stress on the how it is right for an individual to act or be is missing out the important inter-individual, and indeed interenactive, dimension. We would thus propose that an important focus for ethical appraisal is the interaction between people. Indeed we might say that the appraisal of individual agents, while obviously important in ethics, should take place within the context of a crucial consideration of the processes of interaction between agents, where these processes of interaction ought to be (this is a methodological ought) considered as having their own relative autonomy. More will be said about this in due course.

A clarification is necessary here. Many social theorists have pointed out that the actions of individual social agents take place against a background of social norms, rules, expectations, etc., which strongly circumscribe what individual agents actually do, and which constrain the ethical character of the way people act, and also provide a range of possibilities for social action (see Steiner and Stewart, this issue). We leave it as an open question as to what the relation is between the specific, concrete interactions which are the primary focus of our inquiry, and the broader social norms which are the main focus of Steiner and Stewart's essay. We certainly believe that there are intimate connections between these two descriptiveexplanatory social levels. As will be clear from examples to be discussed shortly, the dynamics of participatory sense-making takes place within the context of these broader social norms, and they gain their character partly from this wider context; indeed a key part of the process of sense-making in concrete interactions is that of re-enacting and re-interpreting those inherited social norms in the situation of the current direct interaction. Moreover, these broader social norms often have a strongly ethical character, and help to determine the ethical character of the social interplays that comprise the concrete activity of our day-to-day social life.

Our focus on the directly or concretely interactional draws upon elements of enactive theory as outlined earlier. Thus, we claim, what each of us does in relation to another must, if it is to be fully characterized, be structured in inter-individual or inter-personal terms. What we do and what we mean in what we do-and in particular the ethical significance of what we do and mean - is, to a greater or lesser extent, emergent from the interactions in which we participate (and also, of course, the broader normative structures within which these interactions take place). Thus our actions emerge from a process of collective sense-making that has its own autonomous dynamics, where this dynamics conditions, enables and 
constrains the autonomy of individual agents (see De Jaegher and Di Paolo 2007; Di Paolo, Rohde, and De Jaegher 2009, for an elaboration of these and related ideas).

\section{Agent-Autonomy and Interaction-Autonomy}

Autonomy can be seen in two importantly different ways - as agent-autonomy and as interaction-autonomy. Agent-autonomy can be understood as the partly implicit, partly explicit, ways in which an individual agent maintains a trajectory that enables it to survive, with greater or lesser success, in its physical and social environment. The autonomy of one agent modulates, and is modulated by, the autonomy of others in its interactional space. Agent-autonomy is thus no longer to be seen in terms of an agent's conscious, deliberate actions, which is perhaps how the implicit psychology underlying conventional ethical theories sees it. This new way of looking at agent-autonomy has important implications for ethics; above all, it suggests a defocusing from notions of individual responsibility that often go hand in hand with traditional ethical conceptions of autonomy. In so doing it may also permit or require a defocusing from attendant stances of blame and praise. This will be illustrated in terms of a working example shortly.

Interaction-autonomy, on the other hand, can be described as the way in which the interactional process that takes place between two or more agents has its own, more or less complex, dynamics, which typically has its own independent momentum. This interaction dynamics both affects, and is affected by, the autonomous dynamics of the individual actors. Thus, for example, De Jaegher and Di Paolo discuss in some detail (2007) the kind of unwanted interaction that occurs to two people who find themselves, by happenstance, moving towards each other in a confined space, such as a corridor. As they come towards each other each may, in unison, veer to side A, then to side B, and so on, in a series of mirrored actions. At some point the sequence of matched moves is interrupted somehow, and each can pass the other. Similar situations occur when two people find themselves staring at each other, unable to look away. Such episodes may only last a second or two, or perhaps a fraction of a second.

A key feature of this kind of interaction situation is that there is a coordination of movements between the two participants (De Jaegher and Di Paolo 2007, pp. 490ff), which operates independently of the direction of each of them, and often causing some embarrassment to the actors. The situation has a 'life of its own', and can be characterized as interaction-autonomous. 
This example may seem to be rather trivial. Doesn't it simply involve a case of negotiating an optimal mutual spatial trajectory? What could such a simple, trivial occurrence teach us about the complexities of social (not to mention moral) interaction? In fact, it is precisely because the situation is such a simple one that we are able to see clearly the autonomy of the interactive layer that would be harder to reveal in more complex interactive situations. ${ }^{9}$ Indeed, proponents of the inter-enactive perspective will argue that the key elements of interaction-autonomy illustrated in this seemingly-trivial interaction apply to a very broad range of situations - not just ones to do with simple physical or bodily coordination.

Also, it is important to point out that it is not just dynamics of movement which are negotiated through this autonomous process. There are also complex social and indeed ethical dynamics in play here-broad background socio-cultural norms and assumptions, and more specific concrete-interactional understandings and interpretations. For example, the two participants are (we may suppose) strangers to each other, suddenly forced into an unexpected and unwanted intimacy. Each could reasonably expect the other to be playing broadly similar relevant social roles (for example, if it is in a corporate building, each could be an employee, a visitor, etc.). Each could reasonably expect the other to know that the other would share the expectation that this was a normal day, with no emergency such as a fire or bomb-scare occurring, and so on. Each implicitly adheres to commonly understood ethical norms about how to negotiate each other's personal space (not to simply push the other out of the way; not to treat the other as an interloper or an aggressor; to assume, unless evidence presents itself otherwise, that the other has no other malign motivation, and so on). These various implicit social-ethical norms are reaffirmed and reinterpreted by the agents' interaction. So, even in this very simple kind of case, the interactors find themselves engaged in an implicitly moral transaction, rather than simply a straightforwardly 'physical' manoeuvre, or a social encounter with no ethical overtones.

Thus there are a variety of contextual strands which are understood by the participants, maybe at differing levels of awareness. These strands help to shape how the participants construct (at a rapid speed, it has to be said) a largely shared sense of the social and moral significance of the various key foreground and background elements. Because

\footnotetext{
${ }^{9}$ This is a point on which De Jaegher and Di Paolo (2007) lay particular stress, drawing on the minimalist experimental studies of interpersonal encounter, via tactile avatars, pursued by Charles Lenay and colleagues (Auvray, Stewart, and Lenay 2009)
} 
these constructed understandings are shaped and/or reshaped as a shared product of the interaction, we can see the latter as an additional layer to the interaction-autonomy. ${ }^{10}$

Thus there is autonomy not just at the level of coordinated negotiation of physical movement, but also at the level of coordinated social and, we would claim, ethical meanings. Indeed we may also talk about an autonomous dynamics of meaning. In interactive situations participants do not just bring their ready-made significances to bear on the interaction; significances are implicit in the situation of the encounter (the various social-context factors just mentioned, for instance). There will also be myriad shared, complicit, disputed, resolved, dissolved, rebutted, etc., significances which emerge in a constantly shifting, more or less shadowy way, in any interactional situation. So meaning-negotiation also has its own autonomy and dynamics, as a process which modulates, and is in turn modulated by, the participants' own individually-autonomous authorial perspectives on the situation.

\section{Ethical appraisal}

We thus come to a key step in our argument. A central part of the distinctive contribution that the inter-enactive approach has to offer to an understanding of ethics is that the ethical character of a given situation arises, at least in part, from the meanings which emerge (in a way that is to a greater or lesser degree autonomous) out of the interrelations between the participants in that situation. There can be many different styles of interrelation, dependent upon many factors. The same basic type of encounter can be played out in many different ways. Thus a discussion between a Creationist and a Darwinist can unfold in different ways: as a hostile interaction, where the discussants may take up strongly protected positions; or alternatively as a cordial one, where they rather adopt open-minded, self-sceptical stances; and so on. The participants may start with a pre-defined strategy but, more likely, the stances and strategies that come to be adopted are ones that emerge from the crucible of the joint

\footnotetext{
${ }^{10}$ As mentioned earlier, we leave it as an open question as to what the relation is between concrete interindividual interactions and the broader network of social norms that form the background for such concrete interactions. Steiner and Stewart (this issue) discuss this widescale normative order at some length. In the current paper, to repeat, we are primarily concerned with the face-to-face encounters that are in the foreground to this broader normative order.
} 
encounter. Indeed there may be an alternation, or fluctuation, between different affective and interactive modes, of self- and other-constructions.

The inter-enactive approach thus lays stress on the variety of different modes or styles of interaction between agents. Consideration of these different modes of interaction is crucial for a full understanding of the ethical dimension of our encounters and actions. These different styles of interaction, with their varying affective overtones, will make an ethical difference, in the sense that they will modulate the ethical colouring of any given situation to which categories of ethical description or appraisal may apply. This in turn suggests that an investigation of ethics from an interaction-oriented point of view will enrich accounts of the phenomenology of interaction, by bringing to our attention the endogenously ethical qualities of social interactions.

\section{Case study: Audrey}

We present a short case study as illustration. The following passage centres on interactions between a person with dementia, and a carer. It is taken from a handbook for carers, based on a series of studies made in various UK care homes (Perrin and May 2000).

Audrey has fairly advanced dementia. Two interactions with Audrey are observed: the first by a regular member of the care staff, the second by a volunteer with little prior exposure to caring practice. The two interactions have a strong structural similarity (e.g. both involve a meal-time, and a dyadic encounter), but the style of the interactions is very different in the two cases. So, too, is their ethical character. A chief aim of the passage is to illustrate how very different interactional ethical profiles emerge from the different styles of interaction. The passage indicates how the inter-enactive approach enables a quite different ethical reading of each interaction from that usually found in ethical discourse - a reading which starts first from the quality of the interaction, and only then looks at the qualities of the individual participants.

It was mealtime in the home, and Audrey was wheeled into the lounge. Audrey ... can say only a few phrases (like 'Go to bed', 'I love you' and a few swear words) ... Audrey also has very bright blue, large, expressive, beautiful eyes.

The [first] care assistant ... placed the bowl of splodge on her lap, and started to put spoonfuls into Audrey's mouth - all the while looking out of the window. Audrey's eyes tracked left, right, left, right—looking for a face to hook herself into. 
But there wasn't one, just more faceless spoonfuls of food arriving out of nowhere into her mouth. When she had finished, the careworker stood up, stood over Audrey and wiped her mouth — still with no eye contact, and Audrey's eyes scanning her face.

Later that afternoon, when a new shift was on duty, a punk walked into the day room. She had bright blonde dyed hair, ... lots of earrings, ... Doc Martens. ... She pulled the low stool up next to Audrey, and sat astride it so that her face was right up close to Audrey's face. Audrey beamed as her eyes hooked in with the punk's eyes. Both women were twinkling at each other. Without any words, the punk slowly and gently fed Audrey sips of tea, eyes still locked together and smiling, beaming, deeply communicating. The punk stroked Audrey's face every so often, and Audrey nuzzled in for more.

The punk was new, she hadn't any training and she didn't know that she was keeping Audrey in the world for a little longer. (Perrin and May 2000, p. 51)

There is clearly a marked difference in the style of interaction between the participants in the two cases. The first might be called a 'third-person' interaction: the care assistant treats Audrey as a 'her' rather than a 'you' (or a 'thou'). ${ }^{11}$ There is a disconnect between the participants: a failed search for connection on the part of Audrey, and a refusal to connect on the part of the carer; in addition, each one's 'moves' reinforce the other's. The second interaction, on the other hand, might be called a 'second-person' (or perhaps a 'first-person plural') interaction: a bonding of the two actors into an 'us' for the short time the interaction unfolds. Again, each actor's move reinforces the other, in a more explicit and obvious way than in the first interaction.

Importantly, along with these different styles of interaction comes a strongly contrasting ethical, and indeed affective, character in the two cases. The style of the first interaction has a closed, blocked character. In the first scenario, real coupling and sensemaking between participants is prevented. The carer is not affectively attuned to Audrey, and Audrey's responsivity is frustrated accordingly. In this interaction seemingly, the individual autonomy of both participants is diminished. A reasonable interpretation of the first care worker's style of encounter is that she seems bored by her task, hemmed in by a role she has ceased to identify with (maybe she is simply tired at the end of a long shift). The style of the

\footnotetext{
${ }^{11}$ We leave it open as to whether our interpretation was intended, or would be agreed, by the authors of the book.
} 
second interaction, by contrast, is less conflictual, more open, and more mutually facilitating. There is a strong sense of affective attunement on the part of both participants; the encounter takes off as a wordless dialogue of facial exchange. Reading the description leaves us with a rewarding sense that individual autonomy is being mutually reinforced, and perhaps a hope that the patient might experience a longer-term rehabilitation.

\section{Re-appraising ethical appraisal}

A superficial ethical analysis would see the first carer as having not considered carefully enough the way to achieve the best results for the patient, or as following bad rules, or as having a defective character. Such a view would 'blame' her for poor management of the care situation and for poor treatment of the 'blameless' patient. She 'fails' to provide the kind of affective stimulation that Audrey needs.

A more considered view would see the blocked, frustrated, character of the first episode as emerging from the way the two participants mutually engage with each other, and also as coloured, perhaps, by the way a history of previous episodes has shaped the two participants' responses in the present. To take this less individuocentric approach would be to distance oneself from making judgments of individual responsibility, not because one is denying the autonomy of the participants, but precisely because their interaction is seen as one between beings with a greater/lesser degree of autonomy. Also the more considered approach would concentrate on the interactive-autonomy in the situation as well-for example the way in which Audrey's unsuccessful search for emotional contact and the careworker's attempt to avoid such contact mutually reinforce each other.

A superficial ethical appraisal of the second episode would praise the 'punk' carer for exemplifying (albeit in a spontaneous, untutored way) an appropriate set of skills for acting in a care-situation, and for displaying a sensitive, empathetic cast of character. It would see Audrey as a lucky, but passive, recipient of a happy mix of benevolence and fun on the part of the carer. A more considered view would lay emphasis on how the positive outcomeAudrey's elevated affective arousal and enhanced communication-is not just the product of the care-assistant's unilateral intervention, but is rather constituted out of the higher-level, autonomous dynamic of mutual exchange and coordinated response-patterns that unfold between the interactors. The joyfulness and hope that arises in the second interaction is thus a joint product, not simply the result of an active leader and a passive follower. 
The inter-enactive approach to ethical appraisal suggests that we need to make two shifts:

(a) The first shift is to see the ethical content or valuation of a given situation as emerging as much from the interaction of the participants as from the autonomous decisionmaking or original authorship of the participants themselves. This shift implies a very different way in which ethical appraisal is to be applied in such situations from the way appraisal is conventionally applied. It constrains us to defocus (to a greater or lesser extent) from questions of individual responsibility, exculpation, blame and praise, and encourages us to focus on the ethical qualities of the interaction itself.

To take this point to heart would be likely to have a transformative effect on how we ethically evaluate our own and others' roles in situations. For if action takes shape more in the melting pot of collective extemporization than as an aggregation of individual moves in an interactional chess game, then it appears that we have to be more humble in our ethical appraisals - for two reasons. First we may have to accept a liberal share of co-ownership of what we see as the less attractive features of how others act in a given situation. And second, and conversely, we may have to concede to others in the situation a liberal share of coownership of those aspects of our own acts that seemed to put us in a personally flattering light.

(b) The second shift is in the way we see social interaction itself. This turns out to be not just an interaction between agents who are essentially ethically neutral, where ethical considerations occasionally come in. Rather, it may be that the negotiative dance of participatory sense-making is inevitably ethical in nature: that what we participate in is, to its very bones, an ethical communal sense-making or value-making. Thus ${ }^{12}$ in the process of collective individuation, each one of us in turn individuates himself or herself in a richer way. And this richness may not just be a constitutive richness, but also an ethical richness. This latter idea — at best a conjecture at the moment—needs more elaboration than is possible here. But if it turns out to be a fruitful conjecture, then it would have profound implications for the way in which enactive theories of social interaction are further developed.

\section{Concluding remarks}

\footnotetext{
${ }^{12}$ We here adapt a remark by Charles Lenay made in an email to attendees at the workshop from which this paper developed.
} 
In sum, in this paper we have entered territories that have, for the main part, been looked at only in a cursory way hitherto within the enactive approach. We have used De Jaegher and Di Paolo's (2007) work as our starting point for exploring the affective and ethical nature of participatory sense-making, thus deepening and enriching their approach, as well as elaborating on the links of such an approach to both emotion and ethical theory. In the first part we have focused specifically on the affective dimension of our inter-enactions, arguing that participatory sense-making involves several layers of emotional connectedness, and illustrating this claim with some examples. In the second part we have developed themes in ethical theory that have not been very much discussed by enactive authors, arguing in particular that taking an enactive perspective importantly shifts the focus of ethical appraisal. Although the two parts address different issues in their respective domains, we have also highlighted some important points of cross-fertilization between them. We believe that emotion and ethics are deeply intertwined, specifically that the pervasively affective nature of participatory sense-making determines the ethical character of our encounters; also, we believe that undermining the emotion-cognition distinction as proposed by the enactive approach to sense-making is important for ethical theory, as it can draw attention to practical aspects of ethical know-how in concrete encounters that have tended to be overlooked in the course of the debate between emotion-based and cognition-based approaches.

Both ethical and emotion theory are, of course, very extended areas of research and much more would need to be done to develop a more comprehensive and detailed account of how the inter-enactive approach can contribute to these research fields, and vice-versa. The context from which the present contribution has emerged (the two-day 2008 Powdermills workshop on enactive approaches to social cognition) has nevertheless provided us with the opportunity to inter-enact and to reflect on some of the possible ways in which such an account could be developed, and on identifying some of the themes and issues that could be addressed. As shown by this special issue (and by the discussions we had at the workshop), the enactive approach as originally proposed by Varela, Thompson and Rosch (1991) keeps being a source of inspiration for further reflections on the many facets of mind, life and consciousness, and is constantly being refined and expanded into various domains of inquiry. Our contribution is meant to indicate yet another direction in which this process of refinement and expansion could be taken, and we look forward for further developments within the enactive approach to social cognition to make more room for its affective and emotional dimensions. 


\section{Acknowledgments}

We are indebted to all participants of the 2008 Powdermills workshop for inspiring discussions on these and related issues. We would also like to thank Ezequiel Di Paolo and three anonymous referees for their thoughtful remarks.

\section{References}

Auvray, M., Lenay, C., Stewart, J. (2009). Perceptual interactions in a minimalist environment. New Ideas in Psychology, 27, 79-97.

Ayer, A.J. (1936). Language, Truth and Logic. London: Victor Gollancz.

Ben Ze'ev, A. (1990). Envy and Jealousy. Canadian Journal of Philosophy, 20, 487-517.

Blackburn, S. (1998). Ruling Passions: A Theory of Practical Reasoning. Oxford: Oxford University Press.

Colombetti, G. (2007). Enactive Appraisal. Phenomenology and the Cognitive Sciences, 6, 527-546.

Colombetti, G. (forthcoming). Enaction, sense-making and emotion. In J. Stewart, O. Gapenne, E. di Paolo (Eds.). Enaction: Towards a New Paradigm for Cognitive Science. Cambridge, MA: MIT Press.

Colombetti, G. and Thompson, E. (2008). The feeling body: towards an enactive approach to emotion. In W.F. Overton, U. Müller, J.L. Newman (Eds.). Developmental Perspectives on Embodiment and Consciousness (pp. 45-68). New York: Lawrence Erlbaum Ass.

Damasio, A.R. (1999). The Feeling of What Happens: Body, Emotion and the Making of Consciousness. London: Vintage.

Damasio, A.R. (2003). Looking for Spinoza: Joy, Sorrow and the Feeling Brain. Orlando: Harcourt.

De Jaegher, H., Di Paolo, E. (2007). Participatory sense-making: An enactive approach to social cognition. Phenomenology and the Cognitive Sciences, 6, 485-507.

de Waal, F (2006). Primates and Philosophers: How Morality Evolved. Princeton, NJ: Princeton University Press.

Di Paolo, E.A. (2005). Autopoiesis, adaptivity, teleology, agency. Phenomenology and the Cognitive Sciences, 4, 429-452. 
Di Paolo, E.A., Rohde, M., De Jaegher, H. (2009). Horizons for the enactive mind: Values, social interaction and play. In J. Stewart, O. Gapenne, E. di Paolo (Eds.). Enaction: Towards a New Paradigm for Cognitive Science. Cambridge, MA: MIT Press.

Dimberg, U., Thunberg, M., Elmehed, K. (2000). Unconscious facial reactions to emotional facial expressions. Psychological Science, 11, 86-89.

Dondi, M., Simion, F., Caltran, G. (1999). Can newborns discriminate between their own cry and the cry of another newborn infant? Developmental Psychology, 2, 418-426.

Hatfield, E., Cacioppo, J.T., Rapson, R.L. (1994). Emotional Contagion. Cambridge: Cambridge University Press.

Gallagher, S. (2001). The practice of mind: Theory, simulation or primary interaction? Journal of Consciousness Studies, 8, 83-108.

Goldie, P. (2000). The Emotions: A Philosophical Exploration. Oxford: Clarendon Press.

Hume, D. (1739/2003). A Treatise of Human Nature. London: Dent.

Hutcheson, F. (1728/2003). Essay on the Nature and Conduct of the Passions with Illustrations on the Moral Sense. Kila, MT: Kessinger Publishing Co.

Hutchinson, W.D., Davis, K.D., Lozano, A.M., Tasker, R.R., Dostrovsky, J.O. (1999). Pain related neurons in the human cingulate cortex. Nature Neuroscience, 2, 403-405.

Iglesias, I. (1996). Vergüenza ajena. In R. Harré, G.W. Parrott (Eds.), The Emotions: Social, Cultural and Biological Dimensions (pp. 122-131). London: Sage.

Nussbaum, M. (2001). Upheavals of Thought: The Intelligence of Emotions. Cambridge: Cambridge University Press.

Panksepp, J. (1998). Affective Neuroscience: The Foundations of Human and Animal Emotions. New York: Oxford University Press.

Perrin, T., May, H. (2000). Wellbeing in Dementia: An Occupational Approach for Therapists and Carers. Edinburgh: Churchill Livingstone.

Person, E.S. (1988). Dreams of Love and Fateful Encounters: The Power of Romantic Passion. New York: Penguin.

Reddy, V. (2008). How Infants Know Minds. Cambridge, MA: Harvard University Press.

Sartre, J-P. (1969). Being and Nothingness An Essay on Phenomenological Ontology. London: Routledge.

Shaftesbury, $3^{\text {rd }}$ Earl (1737/1977). Inquiry Concerning Virtue or Merit. Manchester: Manchester University Press. 
Smith, A. (1759/2002). The Theory of Moral Sentiments. Cambridge: Cambridge University Press.

Spinoza, B. de (1677/1996). Ethics. London: Penguin Books.

Stein, E. (1964). On the Problem of Empathy. The Hague: Martinus Nijhoff.

Stern, D.N. (1985/2003). The Interpersonal World of the Infant: A View from Psychoanalysis and Devlopmental Psychology. London: Karnac.

Stevenson, C.L. (1944). Ethics and Language. New Haven, CT: Yale University Press.

Thompson, E. (2001). Empathy and consciousness. Journal of Consciousness Studies, 8, pp. $1-32$.

Thompson, E. (2007). Mind in Life: Biology, Phenomenology, and the Sciences of Mind. Cambridge MA: Harvard University Press.

Thompson, E., Stapleton, M. (2009). Making sense of sense-making: Reflections on enactive and extended mind theories. Topoi, 28, 23-30.

Torrance, S. (2005). Freedom, mind, value: How Spinoza's thought resolves persisting dilemmas over consciousness and ethics. In I.Smit, W.Wallach and G.Lasker (Eds.). Cognitive, Emotive and Ethical Aspects of Decision Making in Humans and in Artificial Intelligence, Vol. IV (pp. 115-124). Windsor, ON: IIAS.

Trevarthen, C. (1979). Communication and cooperation in early infancy: A description of primary intersubjectivity. In M. Bullowa (Ed.). Before Speech: The Beginning of Interpersonal Communication (pp. 321-347). Cambridge: Cambridge University Press.

Varela, F.J. (1992/1999). Ethical Know-How: Action, Wisdom and Cognition. Stanford, CA: Stanford University Press.

Varela, F.J., Thompson, E., Rosch, E. (1991). The Embodied Mind: Cognitive Science and Human Experience. Cambridge, MA: MIT Press.

Wallace, B.A. (2001). Intersubjectivity in Indo-Tibetan Buddhism. Journal of Consciousness Studies, 8, 209-230.

Weber, A., Varela, F.J. (2002). Life after Kant: Natural purposes and the autopoietic foundations of biological individuality. Phenomenology and the Cognitive Sciences, 1, 97125.

Wicker, B., Keysers, C., Plailly, J., Rovet, J.P., Gallese, V., Rizzolatti, G. (2003). Both of us disgusted in my insula: the common neural basis of seeing and feeling disgust. Neuron, 40, 655-664.

Zahavi, D. (2001). Beyond empathy: Phenomenological approaches to intersubjectivity. Journal of Consciousness Studies, 8, 151-167. 
